\title{
Undressing the Ad of Kinder Surprise!
}

\author{
Jana EL Moabbi ${ }^{1}$ \\ ${ }^{1}$ English Language Department, Beirut Arab University, Beirut, Lebanon \\ Correspondence: Jana EL Moabbi, English Language Department, Beirut Arab University, Beirut, Lebanon. \\ E-mail: janaelmoabbi@gmail.com
}

Received: November 6, 2015

doi:10.5539/ass.v13n1p31

\author{
Accepted: February 18, 2016 \\ Online Published: December 20, 2016 \\ URL: http://dx.doi.org/10.5539/ass.v13n1p31
}

\begin{abstract}
This study aims at analyzing a kinder surprise advertisement selected from "the vintage toy advertiser", an Internet magazine. The methodology adopted in the critical examination of the advertisement is the qualitative method that implements Firth's model on the analysis of the layers of meanings in ads. The goal of the analysis is to investigate how children advertisements use semiotics and discourse to make adults and children buy into their ideas, concepts, and products. The investigation shall target the rhetorical strategies and the semiotic features used in the ad to scrutinize the associations the viewers construct from the visual semiotics involved proving how these features are directly responsible for the ideology the ad constructs.
\end{abstract}

Keywords: Rhetorical devices, textual analysis, semiotics, children's advertisements, ideology, Firth's levels of meaning

\section{Introduction}

Children advertisements are intended to convince both children and parents to buy toys, chocolate, or simply any product meant for children. Because these commercials highly influence the minds of children, chocolate adverts try their best to be highly pervasive especially that nowadays we have thousands of different types and brands of children chocolate. The main goal behind chocolate advertising is to drive consumers behavior into buying or demanding no other chocolate but the one seen in the ad. An attractive graphic, a strong headline or a subtle slogan should do the trick.

However, some believe this to be a creative process that should be appreciated, while others consider it to be an unethical and dangerous process that is capable of affecting the minds of children, building ideologies with the ability of corrupting their minds with the messages they construct from the advertisement. This is why, though one cannot deny that advertising is a very creative process, one must also admit that they could be dangerous on our children's minds, and this is why adults should be able to decode advertisements, unmask any intentional or unintentional messages released to help shield our children from danger. For this purpose, this paper attempts to critically analyze one of the Kinder Surprise adverts to unmask the creative strategies used for persuasion, as well as, the negative ideology and messages that the advert intentionally or unintentionally emits to our children.

\section{Research Questions}

1. What are the rhetorical strategies, Linguistic and paralinguistic features that the ad uses? For what purpose?

2. What ideologies(s) is the ad communicating?

3. Is the ad harmful to the minds of children? Why or why not?

\section{Literature Review}

\subsection{Background}

Advertisements are an inherent part of our daily life. They have achieved amazing effects on persuading consumers into buying products. Ads play an important role in selling the goods. Some people call it an art of language using various kinds of devices with a major role of arousing interest, attracting attention, and stimulating purchasing desire. No matter were people are, ads do find their way to consumers, whether through the TVs at home, billboards on the roads, magazines, newspapers, mobile applications, or the net.

\subsection{Advertisements and Meaning Making}

Advertisements are not only economic entities, but they also deal with values, attitudes, and ideas shaping culture 
(Sinclair, 1987). Advertising is a social practice, which does not work in vacuum; it interlinks many things together like person and object, symbol, symbolism and power, and communication and satisfaction (Jhally, 1987). When it comes to analyzing advertisements, especially visual texts, photographs, typed words, font, and color, are all as important as the verbal part. They work a system of signs that interact together to aid in building meaning to the perceiver. The more these signs are used effectively, the more the semiotics is convincing, the more creative and comprehensible the ad is. Semiotic analysis of an ad seeks to find out how the messages are formed and given meaning. Semiotic reference plays an important role in the relationship between the discourse used and the ideology created (Najafian \& Dabaghi, 1991).

\subsection{Firth's Levels of Analysis}

Any commercial has a role to convince people to buy something, even if they had to get them to change their beliefs or ideologies. For this reason, any reviewer of any advertisement should be able to undress the ad. Katherine Firth (1998) discusses a tripartite approach to reading advertising in her book "Undressing the Ad: Reading Culture in Advertising". Firth suggests textual analysis as a useful technique for critically deconstructing both the surface and the deeper social and cultural meaning of adverts. She mentions three levels of analysis. First, comes the surface meaning that the ad holds. It "consists of the overall impression that a reader might get from quickly studying the advertisement" (1998:5). Second is the advertiser's intended meaning which "is the sales message that the advertiser is trying to get across" (ibid). Last is the cultural or ideological meaning that "We all 'make sense' of ads by relating them to our cultural and to the shared belief systems held in common by most people" (ibid).

\subsection{Rhetorical and Visual Semiotics Analysis}

The goal of a rhetorical and visual semiotic analysis is to analyze how the advertiser and creator of the visual is presenting his case, and what ideologies he is spreading. All kind of usage of language, especially in advertising, involves a certain amount of element of persuasion in them. The classic rhetoric theory uncovers the way the element of persuasion works, and how it can be effectively consumed. Furthermore, the use of rhetorical strategies does expose how semiotics plays a role in creating ideologies through advertisements. Visual semiotics, on the other hand, a sub-domain of semiotics, studies the way visual images communicate a message in terms of signs and patterns of symbolism. Since ads nowadays started depending more on images rather than words, and especially when it comes to children ads, visual semiotics become involved.

\subsection{Background on the Product}

The advertisement is promoting a chocolate product for children. The product is Kinder Surprise that is made with chocolate, which contains more than $32 \%$ milk. The product comes in the form of an egg, which turned out to be very appealing for kids. What adds to its appeal is the fact that each egg holds a surprise. The surprise is a collectible toy which is very unique, either one of the characters of the latest Disney film or a toy that can be assembled together to end up with a truck, a pony etc. Kinder Surprise offers three things in one. First, it grants the 'goodness of Kinder chocolate' that is more milk and less cocoa. Second the excitement of the hunting the surprise. There are more than 100 different surprises in each yearly series. The toys are appealing to children and adults with respect to their details, themes, colouring, and assembling. According to Kinder Surprise, every toy is a unique and exclusive creation designed only for Kinder by teams of professionals in child development, psychology, and pathology.

\section{Methodology}

\subsection{Research Design}

A qualitative design was adopted for the study the advertisement of Kinder Surprise, a chocolate egg like product with a toy inside for kids. This advertisement has been selected from the Internet website: thevintagetoyadvertiser.org. This website advertises ads that feature collectible or vintage toys. It featured this ad from 1980 in France. No English language ads for Kinder Surprise were found on this website.

\subsection{Data Analysis}

Firth's Levels of Analysis is the tool used to read and assess the levels of meaning in the ad and show how the advert reflects certain ideologies. Furthermore, a Rhetorical Analysis is also conducted to expose the way the semiotics in the advertisement are used to control children's minds. These analyses shall prove the argument raised on the threat that children advertisements impose on adults and children to buy into their ideas and products, and the dangers of the ideology the ad spreads. 


\section{Data Analysis}

\subsection{Description of the ad}

The ad features a young boy flying in a basket tied up to a balloon with three ropes. The balloon is the product itself, the Kinder Surprise, the milk chocolate egg wrapped in white and red. The little blond happy boy who has trapped three Kinder eggs so far is stretching his arms to collect more eggs scattered in the sky along a white shade crossing the dark blue sky, forming a road like filled with Kinder chocolate eggs. Two of these eggs are illuminating and projecting the surprise toys inside them, the first a clown and the second a vehicle with wheels. The balloon, or the egg itself that is carrying the boy up in the sky, is speaking in French saying "Go for it! Catch the new Kinder Surprise". The font used is all in red, and in big letters. The call out takes the shape of a cloud flying next to the balloon. At the very bottom of the ad is also written in French "The chocolate Surprise" in a white color. The word Surprise, in the ad, is all in white, unlike in the real product.

\subsection{Analysis of Firth's Layers of Meaning}

Firth states that ads hold three different meanings: the surface meaning, the advertiser's intended meaning, and the ideological meaning. The surface meaning in this ad gives the impression, that the boy is so happy catching his chocolate surprise eggs, as the fantasy of every kid is toys and chocolate. The intended meaning of the advertiser is to show children how happy they would be collecting all the Kinder Surprises available. The air balloon that the kid is riding has been considered as one of the most unique ways to see the world's spectacular settings from above.

The advertiser tries to influence children to catch as many (very spectacular) Kinder Surprises as possible and thus affecting them ideologically. This brings us to the third level of meaning, the ideological. Children are made to believe that no matter how many eggs they collect, it is natural and it brings them joy. One boy collecting all these eggs is no longer a sign a mere of happiness and satisfaction, but rather a sign of greedy tendencies, of not having enough, of demanding more than your needs, insufficiency of belongings, selfishness as there is no other kid in the ad to share with all the chocolate and collectible toys. Another thing is the issue of the toys, it is no longer the chocolate that matters, it is the toy that the ad features the most, more than the chocolate itself. The fact that Kinder spends a very big budget yearly on the development of the toys, to make them collectible items, is also a matter of concern that needs to be analyzed. So, the ad echoes the fact that there is no such thing as 'enough' for the kids anymore. Though this falls in the favor of the product holders who are running the ad, it does not fall in favor of our nation, as it is very dangerous to bring our children according to such doctrines and codes.

\subsection{Analysis of the Semiotics and Rhetoric Devices in the Advertisement}

Ideology is associated with concepts such as worldview, the system of beliefs, and values. For this reason, mass media adverts can be understood, in ideological terms, as forms of communication that privilege certain concepts or attitudes and neglect or discard others. Much of the debate nowadays is about the acceptability of the images that the mass media disseminate and their effect on our youngsters.

These debates are mainly over the values the ads focus on, and the implications of their images and the apparent lessons they teach about social codes. One cannot deny that media texts are key sites where basic social norms are articulated. The media give us pictures of social interactions, by their sheer repetition on a daily basis through broadcasts or abundance on billboards and magazines, they can play important roles in shaping character traits (what is normal, accepted, unaccepted, deviant behaviors or lifestyles) and thus broad social manners. Below is an analysis of how the 'Kinder Surprise' ad plays a role in shaping character traits of children while persuading them of the product.

The advertisement employs different rhetorical appeals to persuade the children to buy the chocolate egg. The ad triggers the feelings and emotions of children into believing that catching kinder eggs would make them happy. The ad creates an emotional reaction in the reader. These feelings of happiness, satisfaction, and contempt are invested in persuading the children to demand the product. At the same time, it affects parents into believing that happiness of their children comes with Kinder Surprise. Since pathos corresponds to raising emotions as a technique used for persuasion, we touched on the rhetorical appeal that the ad adopts.

Both linguistic and paralinguistic devices are also used in this advert for the sake of persuasion. Linguistically speaking, not only the brand "Kinder", the German word for children, but also the hollow egg shape of the product with the word 'Surprise' in a bubbly, asif air filled, font are so appealing and do generate a lot of harmony between the brand name and the product. The positivity and warmness of the name along with the bubbly font used for "Kinder Surprise" on the egg itself arousing feelings of lust and yumminess, creates an 
emotional tie between the product and the consumer that is further intensified linguistically with the words" Allez Y! or Go for it! The imperative tone reminds children of their days at the daycare or preschool whenever the teacher guides them in play or singing altogether. That is to say in all fun activities the teacher says, "Go for it!" when she intends to motivate her students. The same can be said for the imperative use of the verb "catch". Catching is all related to balls or egg hunting, activities related to fun. Other than the font, another paralinguistic feature would be the use of the blue color for the background of the ad. The blue color representing the sky denotes innovation, which further certifies the novelty of 'Kinder surprise', the fact that it is the first chocolate brand that offers its milk and chocolate with a collectible "vintage' toy. The "S" in the word Surprise in the call out, has a very special design in this font. Both curves in the letter " $\mathrm{S}$ " are a bit spiral like, a significance of illusions and fantasy that are linked to fun (amusement parks and rides). At the very bottom of the ad is also written in French "The chocolate Surprise", but with a different font, that is more formal, white in color, and less dynamic signifying a less focus or interest on the chocolate itself. The word Surprise, in the ad, is all in white, unlike in the real product.

As you have seen, linguistic and paralinguistic features, have been exploited to influence the viewers emotionally and ideologically. The idea of the toy surprises that have been considered as collectible items, vintages, with the way the toys are portrayed all aid in building a relationship between the viewer and the product, as these visuals do create a passion for the object and make it easier to persuade consumers about it. Ideologically speaking, one cannot overlook the fact that the persuasion in the ad and the pathos created are actually based on feelings of desire and seduction.

\subsection{The Ideology the ad Spreads}

The analysis of this Kinder Surprise advert signals that it can ideologically affect children as well as parents in several ways. First, the hollow chocolate egg demonstrates a desire for something beyond the thing we need, the hollow chocolate shell is discarded for another plastic yellow shell, the one holding the toy inside. This is very dangerous as it unconsciously drives us into replacing one item of desire with another. In this way, and according to Salvoj Žižek, a basic structure of desire becomes controlled by the commodity: Kinder Surprise offers the 'something more' (the collectible toy surprise) beyond the initial object purchased, but discarded or neglected (the chocolate) for it. Another dangerous factor the advert promotes is the fact that when children pursue the chocolate egg for the sake of the toy, as we see with many children who are not interested in consuming the chocolate, but rather in playing with toy, the advert becomes about pure consumerism then, without any claim to use the value of the product itself. It is a matter of pure excitation of desire. Third, the ad teaches children to become greedy individuals in our society. The ad features only one chubby happy boy, who has already collected three Kinder Surprises, and is still stretching his arms from the basket attached to the balloon, to collect all the eggs that are only scattered on the path of the balloon flying in the sky. This is a mere distortion of fundamental life values. Fourth, the promotional appeal of the toy induces the child to eat in exchange of the reward. So, children start eating not because they want to eat, but just to be rewarded. Last but not least, the absence of another child to share the vintage toy with does not encourage children to socialize when it comes to Kinder Surprise and its toy.

\section{Findings}

Advertisers create a plan to attract the attention of a determined public about a product in order to sell it. In the case of children marketing, the objective is to mobilize childhood fantasies, so that the child desires the product with great intensity to a point that convinces the parents that it getting it will grant him or her a lot of happiness. By doing this, advertising is fabricating empty concepts of happiness. This concept becomes linked to developing habits of consumption which can be considered as a bad and sometimes a dangerous habit when it grows out of control and becomes consumption for consumption's sake, especially when the items consummated do not offer complete satisfaction. Furthermore, this would lead to the distortion of social, ethical, and moral values that we try to raise our kids to. Kids might stop sharing, develop selfish needs and greed, and become mere consumers of undesired products. So, they become easy targets for advertisers, can be easily influenced into any concept with the use of proper graphics, logo, rhetorical devices, and linguistic and paralinguistic features.

\section{Conclusion}

Linguistic researchers analyze the rhetorical devices, the linguistic and paralinguistic features of visual texts to study the ideology of adverts. They are interested in studying or analyzing the way these features are employed in adverts to transmits ideologies, affect the minds of the people into buying their product, the values that the advertisements legitimize, and the kinds of behaviors that are deemed normal. This paper studied these features 
with respect to the 'Kinder Surprise ad' to uncover the values and the ideology the children chocolate advert was passing to our children. This integrated analysis of the advert, verifies that it is very important thing is that our observation does not become a passive acceptance of ideas, and for this reason we must pass what we are shown through the prism of our perception and minds before accepting the "truths" offered. That is why; it is crucial that we understand the implications that advertisements have on our lives, so that neither we, nor our children become mere objects of manipulation.

\section{References}

Cook, G. (1992). The Discourse of Advertising. 5. London: Routledge.

Firth, K. (1998). Undressing the Ad: Reading Culture in Advertising. Peter Lang International Academic Publishers.

Jhally. (1987). The codes of Advertising. Routledge; Reprint edition (December 12, 1990).

Najafian and Dabaghi. (1991). Hidden Language of Advertising: A Semiotic Approach. Proceedings of the International Conference: Doing Research in Applied Linguistics

Sinclair, J. McH. (1987). In Language Topics: Essays in honour of Micheal Halliday. Edited by Ross Steele and Terry Threadgold. [Not in series, LT 1] (p. 319)

The Vintage Toy Advertiser. Retrieved from http:/thevintagetoyadvertiser.org/category/kinder-surprise/

Williamson, J. (2002). Decoding advertisements: ideology and meaning in advertising. London: Marion Boyars.

Žižek, S. (2009). The Sublime Object of Ideology. Verso; Second Edition.

\section{Appendix A}

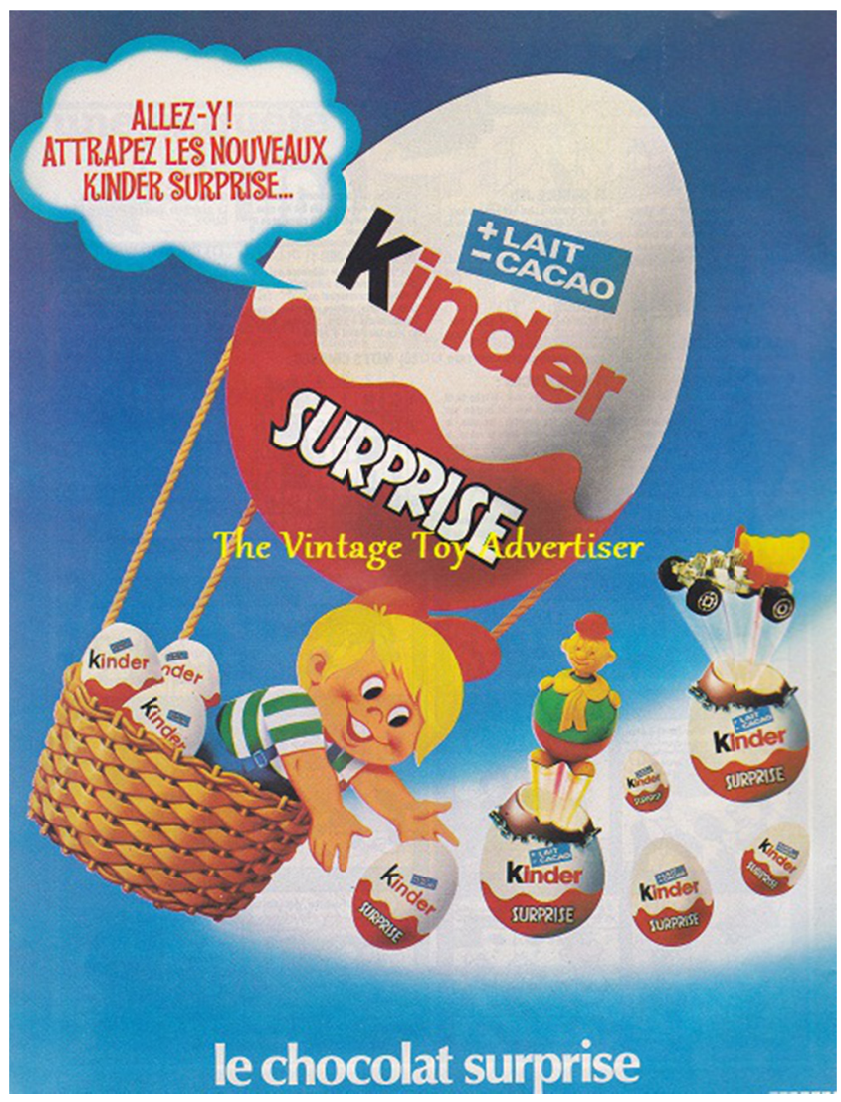

\section{Copyrights}

Copyright for this article is retained by the author(s), with first publication rights granted to the journal.

This is an open-access article distributed under the terms and conditions of the Creative Commons Attribution license (http://creativecommons.org/licenses/by/4.0/). 